\title{
Invasive meningococcal disease due to a non-capsulated Neisseria meningitidis strain in a patient with IgG4-related disease
}

Shun Kurose ${ }^{1}$, Kyoko Onozawa ${ }^{1 *}$, Hiroshi Yoshikawa ${ }^{2}, K^{\prime}$ Kenichiro Yaita ${ }^{3}$, Hideyuki Takahashi ${ }^{4}$, Nobuyuki Shimono ${ }^{5}$ and Yoji Nagasaki ${ }^{1}$

\begin{abstract}
Background: Invasive Meningococcal Disease (IMD) is a rare and critical disease in Japan. Most of these cases are caused by capsulated Neisseria meningitidis strains. Non-capsulated (non-typable) strains are considered relatively lowpathogenic and can colonize in the nasopharynx of healthy children and young adults. As far as could be ascertained, only twelve IMD cases due to non-capsulated strains have been reported in the literature. No clear risk factors could be identified in a literature review (unknown or immunocompetent, seven cases; C6 deficiency, three cases).

Case presentation: We report a Japanese male taxi driver with bacteremia and meningitis due to non-capsulated $\mathrm{N}$. meningitidis. He had a fever and shaking chills. Ceftriaxone was administered, and the patient finally recovered. During the clinical course, relative adrenal insufficiency occurred and was treated with hydrocortisone. A hidden co-morbidity, immunoglobulin G4 (IgG4)-related disease, was revealed in the past surgical history (a resection of bilateral orbital tumors), which included symptoms (swelling lachrymal glands and lymph nodes), elevated lgG4, immunoglobulin E, and hypocomplementemia. He recovered finally and no recurrence was observed.

Conclusions: Our IMD case is the first reported in Japan, where IMD is not considered pandemic. The patient had a history of IgG4-related disease, although we could not establish a clear relationship between the patient's IMD and comorbidity. A collection of further clinical cases might establish the risk factors and characteristics of IMD that could be caused by this neglected pathogen, non-capsulated N. meningitidis.
\end{abstract}

Keywords: Invasive meningococcal disease, Non-capsulated Neisseria meningitidis, IgG4-related disease, Hypocomplementemia

\section{Background}

Invasive Meningococcal Disease (IMD) is a critical disease caused by Neisseria meningitidis. In Japan, IMD was listed as a notifiable disease in April 2013. Approximately 60 cases were reported to Japanese national surveillance from April 2013 to December 2014 [1].

$N$. meningitidis causing IMD usually have the capsule [2]. Encapsulated bacteria are resistant to humoral immunity and have a tendency to disseminate hematogenously. On the other hand, non-capsulated (non-typable) $N$. meningitidis strains are not resistant to opsonization and seldom cause invasive infection in healthy humans. Therefore, a search of the literature reveals only a small number of case reports of IMD due to non-capsulated N. meningitidis.

As far as we could ascertain, this is the first Japanese case of IMD due to non-capsulated $N$. meningitidis. The patient had an underlying diagnosis of immunoglobulin G4 (IgG4)-related disease. By describing this case and the review of the past literature, we discuss the neglected pathogen, non- capsulated N. meningitidis. And we consider the possible relationship between IMD and IgG4related disease.

\footnotetext{
* Correspondence: kyouko.onozawa@gmail.com

${ }^{1}$ Division of Infectious Diseases, Fukuoka City Hospital, 13-1

Yoshizuka-Honmachi, Hakata-ku, Fukuoka 812-0046, Japan

Full list of author information is available at the end of the article
} 


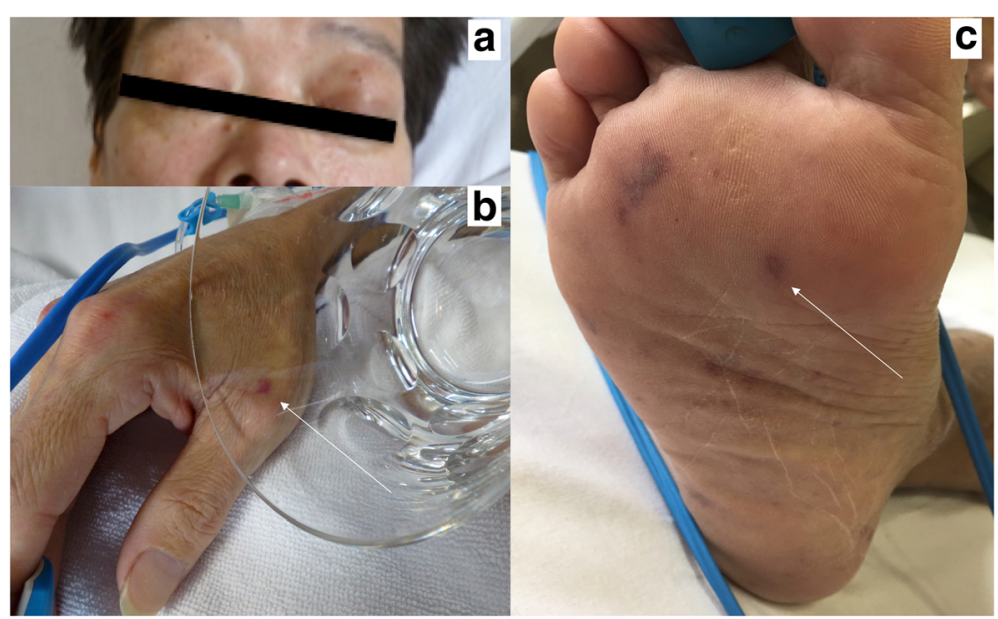

Fig. 1 A swelling of bilateral eyelids (a) and purpura and petechiae on the limbs (b, c)

\section{Case presentation}

A 51-year-old male taxi driver was admitted to Fukuoka City hospital with high fever $\left(40^{\circ} \mathrm{C}\right)$ and a shaking chill despite his use of over-the-counter antipyretics. He was transferred to the emergency department about $14 \mathrm{~h}$ after the symptoms onset. His medical history included bronchial asthma, pneumonia, and a surgical procedure for the resection of bilateral orbital tumors at 40 years of age. The patient had neither a history of contact with sick persons nor of any travel abroad. His body height was $160 \mathrm{~cm}$ and his body weight was $52 \mathrm{~kg}$.

At the time of admission, his vital signs were as follows: blood pressure, 108/74 $\mathrm{mmHg}$; heart rate, 90 beats/min; respiratory rate, 40 breaths/min; body temperature, $40.1^{\circ}$
C; and Glasgow Coma Scale, E4V4M6 (total 14/15). Upon physical examination, a swelling of the bilateral eyelids (Fig. 1a) and petechiae were detected on the conjunctiva. Some dental caries, purpura and petechiae were noted on the limbs (Fig. 1b, c), and 1-2 cm sized swollen lymph nodes noted at submandibular and inguinal areas were remarkable. Neck stiffness was not detected. Laboratory data on admission revealed high inflammation (white blood cell 13,500 $\mu \mathrm{L}$, and c-reactive protein $12.29 \mathrm{mg} / \mathrm{dL}$ ), normocytic anemia (Hemoglobin $8.7 \mathrm{~g} / \mathrm{dL}$ ), high protein and low albumin levels (total protein $12.3 \mathrm{~g} / \mathrm{dL}$ and albumin $2 \mathrm{~g} / \mathrm{dL}$ ), renal failure (serum creatinine $4.52 \mathrm{mg} / \mathrm{dL}$ ), hyperkalemia $(6.12 \mathrm{mEq} / \mathrm{L})$, proteinuria and hematuria (Table 1). Computed tomography showed enlargement of

Table 1 The laboratory data of the patient

\begin{tabular}{|c|c|c|c|c|c|c|c|c|}
\hline \multicolumn{3}{|l|}{ Hematology } & \multicolumn{3}{|c|}{ Chemistry } & \multicolumn{3}{|l|}{ Serology } \\
\hline WBC & 13,500 & $/ \mu l$ & $\mathrm{TP}$ & 12.3 & $\mathrm{~g} / \mathrm{dl}$ & $\lg G$ & 7392 & $\mathrm{mg} / \mathrm{dl}$ \\
\hline Neutro & 84.5 & $\%$ & Alb & 2 & $\mathrm{~g} / \mathrm{dl}$ & $\lg G 4$ & 3200 & $\mathrm{mg} / \mathrm{dl}$ \\
\hline Lymph & 9.6 & $\%$ & Glu & 69 & $\mathrm{mg} / \mathrm{dl}$ & $\lg A$ & 78 & $\mathrm{IU} / \mathrm{ml}$ \\
\hline $\mathrm{Hgb}$ & 8.7 & $\mathrm{~g} / \mathrm{dl}$ & T-Bil & 0.37 & $\mathrm{mg} / \mathrm{dl}$ & ANA & $<\times 40$ & \\
\hline $\mathrm{HCT}$ & 25.9 & $\%$ & AST & 13 & $\mathrm{IU} / \mathrm{I}$ & SS-A & 7.8 & $\mathrm{U} / \mathrm{ml}$ \\
\hline PLT & 15.4 & $10^{4} / \mu l$ & $\mathrm{ALT}$ & 26 & $\mid \mathrm{IU} / \mathrm{I}$ & SS-B & $\leqq 7.0$ & $\mathrm{U} / \mathrm{ml}$ \\
\hline Coagulation & & & $\mathrm{LDH}$ & 282 & IU/I & $\mathrm{CH} 50$ & $<12.0$ & $\mathrm{U} / \mathrm{ml}$ \\
\hline PT \% & 40 & $\%$ & CK & 123 & $\mathrm{IU} / \mathrm{I}$ & C3 & 37 & $\mathrm{mg} / \mathrm{dl}$ \\
\hline APTT & 48.6 & $\mathrm{sec}$ & BUN & 46.3 & $\mathrm{mg} / \mathrm{dl}$ & C4 & 7 & $\mathrm{mg} / \mathrm{dl}$ \\
\hline FDP & 10.5 & $\mu \mathrm{g} / \mathrm{ml}$ & Cre & 4.52 & $\mathrm{mg} / \mathrm{dl}$ & $\mathrm{ACTH}$ & 66.9 & $\mathrm{pg} / \mathrm{ml}$ \\
\hline Urinalysis & & & $\mathrm{Na}$ & 125 & $\mathrm{mEq} / \mathrm{l}$ & Cortisol & 16.7 & $\mu \mathrm{g} / \mathrm{dl}$ \\
\hline Protein & $(1+)$ & & K & 6.12 & $\mathrm{mEq} / \mathrm{l}$ & SIL-2R & 5390 & $\mathrm{U} / \mathrm{ml}$ \\
\hline Blood & $(1+)$ & & $\mathrm{Cl}$ & 102 & $\mathrm{mEq} / \mathrm{l}$ & Procalcitonin & $>10$ & $\mathrm{ng} / \mathrm{mL}$ \\
\hline Bence-Jones protein & $(-)$ & & CRP & 12.29 & $\mathrm{mg} / \mathrm{dl}$ & & & \\
\hline$\beta 2$-microglobrin & 103,000 & $\mu g / l$ & & & & & & \\
\hline
\end{tabular}




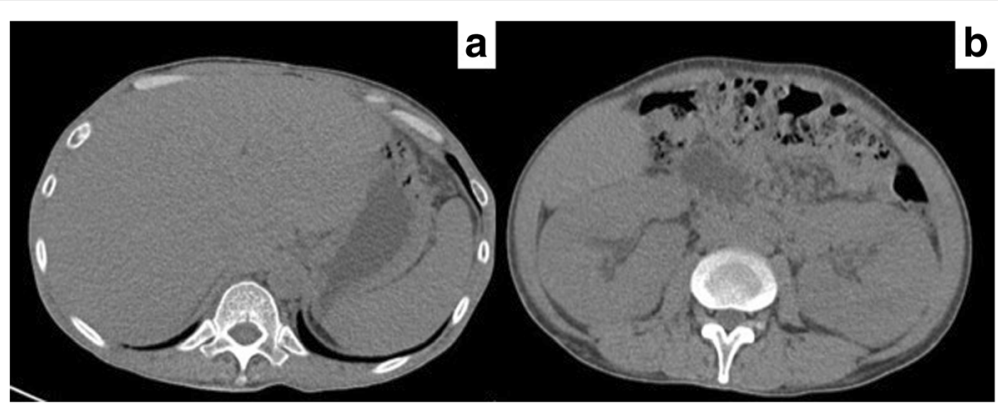

Fig. 2 The enlargement of liver and bilateral kidneys $(\mathbf{a}, \mathbf{b})$ detected by using computed tomography

the liver and bilateral kidneys (Fig. 2a, b) in addition to swelling of the cervical, supraclavicular, axillary, mediastinal, and celiac lymphadenopathy.

Severe infectious disease was suspected, and we started ceftriaxone $1 \mathrm{~g}$ intravenously every $12 \mathrm{~h}$ after drawing a blood culture. However, purpura spread rapidly and the progression of drowsiness and fever was sustained on the 2nd hospital day. We performed a lumbar puncture and the turbid spinal fluid analysis revealed meningeal inflammation (white blood cell count, 2370 /fields; protein, $293 \mathrm{mg} / \mathrm{dL}$; and glucose, $16 \mathrm{mg} / \mathrm{dL}$ ), which was compatible with bacterial meningitis (Fig. 3). Gramstaining of the spinal fluid showed gram-negative diplococci. The blood culture also became positive for gramnegative diplococci. We strongly suspected that the septic status of the patient's meningitis and bacteremia was due to $N$. meningitidis. We increased the dose of ceftriaxone to $2 \mathrm{~g}$ intravenously every $12 \mathrm{~h}$. The patient's general status and consciousness then improved and his fever subsided. On the 5th hospital day, the patient's fever $\left(38{ }^{\circ} \mathrm{C}\right)$ re-appeared with hypotension, hyponatremia and eosinophilia, which led to a suspicion of relative adrenal insufficiency due to meningococcemia. We started a daily intravenous administration of $300 \mathrm{mg}$ hydrocortisone on the 7th hospital day, and tapered the regimen to a daily oral administration of hydrocortisone on the 11th hospital day. Ceftriaxone was stopped on the 12th hospital day. No recurrence of infection was observed and he was discharged on the 25th hospital day. The clinical course is summarized in Fig. 4.

We investigated the patient's co-morbidities and performed microbiological analysis of the strain. His past surgical history (bilateral orbital tumors), his symptoms (swelling lachrymal glands and lymph nodes), the elevated levels of IgG4 (3200 mg/dL) and immunoglobulin E (304 IU/ml), and hypocomplementemia (C3 $37 \mathrm{mg} / \mathrm{dL}$, $\mathrm{C} 47 \mathrm{mg} / \mathrm{dL}$, and $\mathrm{CH} 50<12.0 \mathrm{U} / \mathrm{ml}$ ) were the characteristics of Mikulicz's disease included in IgG4-related disease. Furthermore, a biopsy of the patient's lymph nodes confirmed the presence of IgG4-related disease (IgG4/ IgG index 100\%). We prescribed oral prednisolone
$30 \mathrm{mg}$ a day on the 19th hospital day. In addition, the strain of $N$. meningitidis was identified as non-typable. The sequence type (ST) was identified as ST-11448, which belongs to ST-23 (ST-23 complex), the most common ST in Japan [3]. Moreover, we also analyzed the $N$. meningitidis strain according to PorA and FetA typing, which has a higher resolution power than that of ST, and identified that the PorA VR1, PorA VR2 and FetA were 5, 2-82, and F4-1, respectively. These results suggested that this $N$. meningitidis strain was a non-

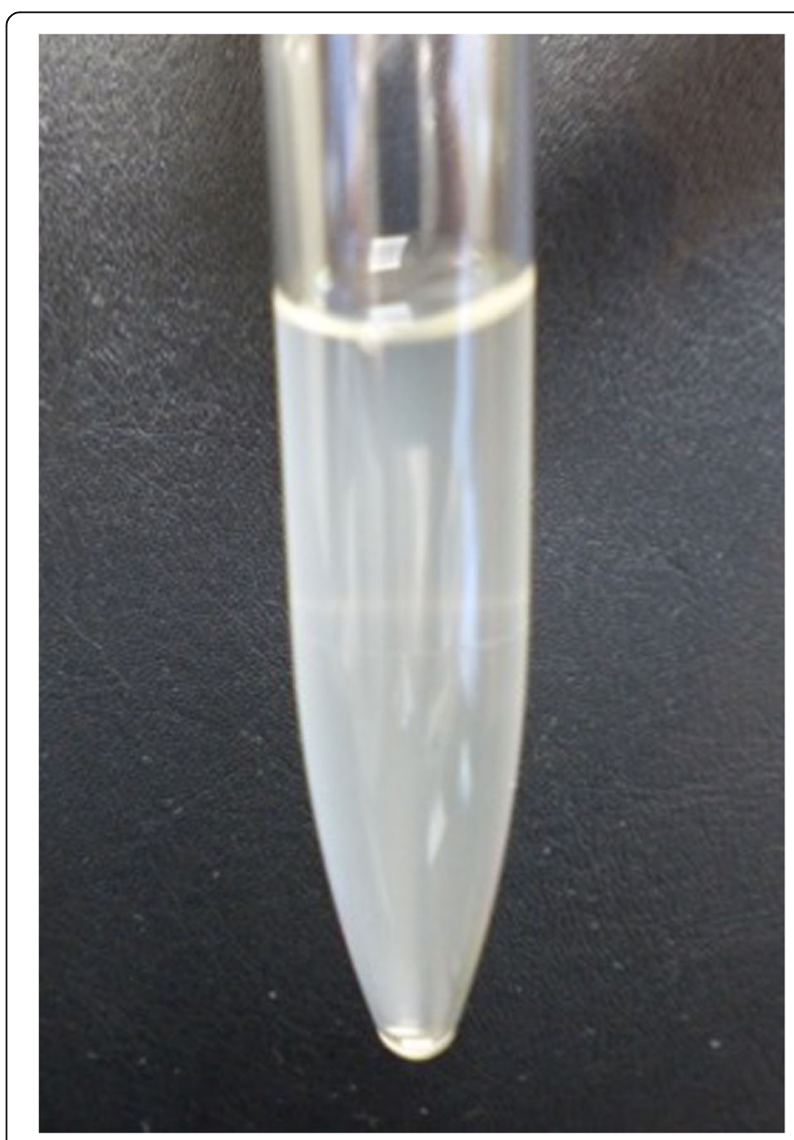

Fig. 3 A lumbar puncture was performed and the turbid spinal fluid was collected 


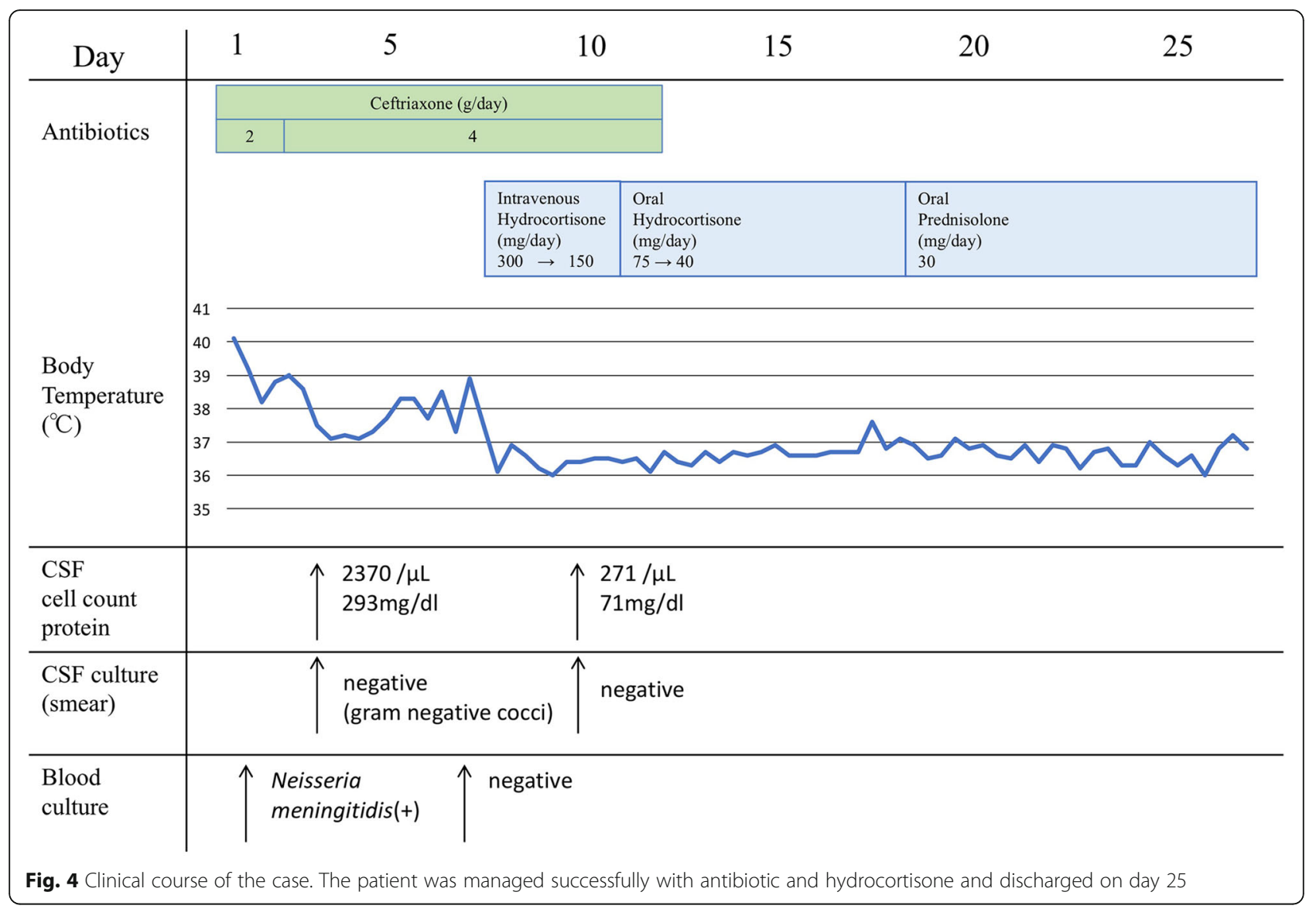

capsulated derivative of the domestic ST-23 strain. (See Discussion and conclusion).

\section{Discussion and conclusion}

As far as we could ascertain, this is the first Japanese case among IMD cases due to non-typable $N$. meningitidis.
This is also the first case of $N$. meningitidis causing IMD in a patient with IgG4-related disease.

The mechanism of $N$. meningitidis infection relies on three factors to avoid the human immune response system: the formation of a capsule, the production of IgA protease, and molecular mimicry. Among these factors,

Table 2 The previous reports of invasive meningococcal disease cases due to non-typable Neisseria meningitidis

\begin{tabular}{|c|c|c|c|c|c|}
\hline Case & Age & Sex & Risk Factor & Result of Culture & $\overline{\text { Outcome }}$ \\
\hline \multirow[t]{2}{*}{ Hummell DS, et al. 1987 [7] } & 0 & $M$ & C6 deficiency & CSF: positive Blood:negative & Survive \\
\hline & 0 & M & C6 deficiency & CSF: positive Blood:negative & Survive \\
\hline Vogel U, et al. 2004 [4] & 42 & - & ALL, GVHD & Blood: positive & Survive \\
\hline Hoang LM, et al. 2005 [9] & 13 & $\mathrm{~F}$ & Immunocompetent & CSF: positive, Blood: negative & Death \\
\hline \multirow[t]{3}{*}{ Findlow H, et al. 2007 [8] } & 12 & M & Unknown & CSF: positive & Survive \\
\hline & 13 & M & Unknown & CSF: positive & Survive \\
\hline & 11 & $\mathrm{~F}$ & Unknown & CSF: positive & Survive \\
\hline Johswich KO, et al. 2012 [10] & 13 & M & Unknown & Blood: positive & Unknown \\
\hline Zheng Xu, et al. 2015 [11] & 7 & $\mathrm{~F}$ & Immunocompetent & Blood: positive & Survive \\
\hline \multirow[t]{3}{*}{ Ganesh K, et al. 2017 [12] } & $45-64^{\mathrm{a}}$ & M & Diabetes mellitus COPD & Pleural aspirate: positive & Survive \\
\hline & $15-24^{\mathrm{a}}$ & M & Unknown & CSF: positive & Survive \\
\hline & $5-9^{a}$ & M & C6 deficiency & Blood: positive CSF: positive & Survive \\
\hline
\end{tabular}

F female, $M$ male, ALL Acute lymphoblastic leukemia, GVHD graft versus host disease, COPD chronic obstructive pulmonary disease, CSF cerebrospinal fluid ${ }^{a}$ The age of three patients in reference [12] were described as age category 
the formation of a capsule contributes the most to the progression of IMD [4]. A capsule can prohibit opsonophagocytosis in the human body. Twelve serogroups of N. meningitidis (A, B, C, Y, W, X, Z, 29E, H, I, J, L) were divided according to the antigenicity. Among these serogroups, the five (A, B, C, Y, W) make up the majority of IMD causative pathogens, for which vaccines are available [5]. On the other hand, non-typable strains are considered to be of low-pathogenicity [6].

Only 12 IMD cases due to non-typable strains could be found in a literature review by using PubMed and Ichushi (the Japanese database for medical literature and conference proceedings) databases (Table 2) [4, 7-12]. Although the risk factors of most cases are unknown, three C6 deficiency (hypocomplementemia) cases are described in the literature $[7,12]$. Hypocomplementemia is an established risk factor of IMD [13]; however, there has been no report of the relationship between hypocomplementemia and IMD due to non-typable bacteria. Opsonophagocytosis with antibodies and complements is thought to prevent the invasion of non-capsulated bacteria [13].

The laboratory data in our case revealed hypocomplementemia. At first, we suspected that hypocomplementemia appeared secondary due to sepsis [14]. However, because the patient's vital signs did not reach the level of shock status [14], hypocomplementemia was considered to be secondary to the patient's sole medical background, IgG4-related disease. Hypocomplementemia is a characteristic of IgG4-related disease; however, that does not suggest increased susceptibility to infection. Also, the patient had not taken immunosuppressive agents such as corticosteroids. We finally concluded that this was an accidental occurrence of IMD in this patient with IgG4-related disease. There remains the possibility that his job (taxi driver) was associated with the acquisition of the pathogen due to close contact with many persons. In a German study, $1.7 \%$ of healthy children and young adults possessed the non-capsulated $N$. meningitidis in their pharynx [6].

Based on a microbiological viewpoint of $N$. meningitidis, ST-11448 has a difference of only 1 nucleotide in the fumC gene (G at 207 to C) compared with those in ST-23 strain; however, this strain was uniquely recorded as ST-11448 in the MLST database at the time of Feburuary 2018 [15]. In addition, according to the Neisseria PorA and FetA typing database, [16, 17] 43 meningococcal strains were recorded as PorA VR1: 5 and FetA: F41 , and among those, only one strain had been isolated in Sweden 2006, belonged to ST-23. On the other hand, a meningococcal strain listed as PorA VR2: 2-82 could not be found in the database. Taking the molecular epidemiological resolution of PorA and FetA typing into consideration, these microbiological results suggested that this $N$. meningitidis strain was a non-capsulated derivative of a domestic ST-23 strain rather than one imported from outside Japan.

In conclusion, this is the first documented case of IMD with non-typable N. meningitidis in Japan. Since the patient had no immunosuppressive drugs and the underlying disease was not considered to be an immunocompromising condition, we concluded that IMD had developed accidentally. This non-typable strain is considered to be low-pathogenic and few cases have been reported. We intend to collect more clinical cases that will allow us to establish the characteristics of IMD caused by this neglected pathogen.

Abbreviations

IgG4: limmunoglobulin G4; IMD: Invasive Meningococcal Disease

\section{Acknowledgements \\ None.}

\section{Funding}

The microbiological analysis in this case report was supported by Grants-inAid for Scientific Research (KAKENHI) Grant Number 15 K08485.

\section{Availability of data and materials}

All data containing relevant information to support the study findings are included in the manuscript.

\section{Authors' contributions}

SK, KO, HY and YN are the attending physicians for the patient and collected medical data of the patient. HT performed microbiological analysis of the clinical sample. SK and KO wrote the manuscript. KY and NS made a critical revision of this manuscript. All authors read and approved the final manuscript.

Ethics approval and consent to participate

Not applicable.

\section{Consent for publication}

Written informed consent was obtained from the patient for publication of his medical and personal details including all accompanying images.

\section{Competing interests}

The authors declare that they have no competing interests.

\section{Publisher's Note}

Springer Nature remains neutral with regard to jurisdictional claims in published maps and institutional affiliations.

\section{Author details}

${ }^{1}$ Division of Infectious Diseases, Fukuoka City Hospital, 13-1 Yoshizuka-Honmachi, Hakata-ku, Fukuoka 812-0046, Japan. ²Department of Ophthalmology, Graduate School of Medical Science at Kyushu University, Fukuoka, Japan. ${ }^{3}$ Division of Infection Control and Prevention, Kurume University Hospital, Kurume, Japan. ${ }^{4}$ Department of Bacteriology I, National Institute of Infectious Diseases, Tokyo, Japan. ${ }^{5}$ Center for the Study of Global Infection, Kyushu University Hospital, Fukuoka, Japan.

Received: 12 December 2017 Accepted: 26 March 2018 Published online: 02 April 2018

\section{References}

1. Trends in invasive meningococcal disease, week 13, 2013 to week 52, 2014, Japan. National Institute of Infectious Diseases. https://www.niid.go.jp/niid/ ja/bac-megingitis-m/bac-megingitis-iasrs/5864-pr4271.html. Accessed 5 Nov 2017. (in Japanese). 
2. Jafri RZ, Ali A, Messonnier NE, Tevi-Benissan C, Durrheim D, Eskola J, et al. Global epidemiology of invasive meningococcal disease. Popul Health Metr. 2013;11:17.

3. Takahashi H, Kuroki T, Watanabe $Y$, Tanaka H, Inouye H, Yamai S, et al. Characterization of Neisseria meningitidis isolates collected from 1974 to 2003 in Japan by multilocus sequence typing. J Med Microbiol. 2004;53: 657-62.

4. Vogel U, Claus H, von Müller L, Bunjes D, Elias J, Frosch M. Bacteremia in an immunocompromised patient caused by a commensal Neisseria meningitidis strain harboring the capsule null locus (cnl). J Clin Microbiol. 2004;42:2898-901.

5. Caugant DA, Maiden MC. Meningococcal carriage and disease-population biology and evolution. Vaccine. 2009;27(Suppl 2):B64-70.

6. Claus H, Maiden MC, Maag R, Frosch M, Vogel U. Many carried meningococci lack the genes required for capsule synthesis and transport. Microbiology. 2002;148:1813-9.

7. Hummell DS, Mocca LF, Frasch CE, Winkelstein JA, Jean-Baptiste HJ, Atilio Canas J, et al. Meningitis caused by a nonencapsulated strain of Neisseria meningitidis in twin infants with a C6 deficiency. J Infect Dis. 1987;155:815-8.

8. Findlow H, Vogel U, Mueller JE, Curry A, Njanpop-Lafourcade BM, Claus H, et al. Three cases of invasive meningococcal disease caused by a capsule null locus strain circulating among healthy carriers in Burkina Faso. J Infect Dis. 2007:195(7):1071.

9. Hoang LM, Thomas E, Tyler S, Pollard AJ, Stephens G, Gustafson L, et al. Rapid and fatal meningococcal disease due to a strain of Neisseria meningitidis containing the capsule null locus. Clin Infect Dis. 2005;40:e38-42.

10. Johswich KO, Zhou J, Law DK, St Michael F, McCaw SE, Jamieson FB, et al. Invasive potential of nonencapsulated disease isolates of Neisseria meningitidis. Infect Immun. 2012;80:2346-53.

11. $\mathrm{Xu} Z$, et al. First case of Neisseria meningitidis capsule null infection in China. Infect Dis (Lond). 2015;47:591-2.

12. Ganesh K, Allam M, Wolter N, Bratcher HB, Harrison OB, Lucidarme J, et al. Molecular characterization of invasive capsule null Neisseria meningitidis in South Africa. BMC Microbiol. 2017:17:40.

13. Lewis LA, Ram S. Meningococcal disease and complement system. Virulence. 2014:5:98-126.

14. Hebert LA, Cosio FG, Neff JC. Diagnostic significance of hypocomplementemia. Kidney Int. 1991;39:811-21.

15. PubMLST. Neisseria Sequence Typing Home Page. https://pubmlst.org/ neisseria/. Accessed 23 Feb 2018.

16. PubMLST. Neisseria PorA Typing. https://pubmlst.org/neisseria/PorA/. Accessed 23 Feb 2018.

17. PubMLST. Neisseria FetA variable region typing. https://pubmlst.org/ neisseria/FetAV. Accessed 23 Feb 2018

\section{Submit your next manuscript to BioMed Central and we will help you at every step:}

- We accept pre-submission inquiries

- Our selector tool helps you to find the most relevant journal

- We provide round the clock customer support

- Convenient online submission

- Thorough peer review

- Inclusion in PubMed and all major indexing services

- Maximum visibility for your research

Submit your manuscript at www.biomedcentral.com/submit 